\section{Growth of Rooted 'Gala' Apple Microcuttings ex Vitro as Influenced by Initial Adventitious Root Count}

\author{
Dennis P. Stimart ${ }^{1}$ and James F. Harbage ${ }^{2}$ \\ Department of Horticulture, 1.57.5 Linden Drive, University of Wisconsin, \\ Madison, WI 53706
}

Additional index words. auxin, $\mathrm{pH}$, propagation, micropropagation, tissue culture, Malus domestica

Abstract. The role of the number of adventitious roots of Malus domestics Borkh. 'Gala' microcuttings in vitro on ex vitro root and shoot growth was investigated. Root initiation treatments consisted of IBA at $0,0.15,1.5,15$, and $150 \mu \mathrm{M}$ in factorial combination with media at $\mathrm{pH}$ 5.5,6.3, and 7.0. IBA concentrations significantly influenced final root count and shoot fresh and dry weights, but not plant height, leaf count, or root fresh and dry weights at 116 days. Between 0 and $0.15 \mu \mathrm{M}$ IBA, final root counts were similar, but at 1.5, 15 , and $150 \mu \mathrm{M} I \mathrm{IBA}$, root counts increased by $45 \%, 141 \%$, and $159 \%$, respectively, over the control. The pH levels did not affect observed characteristics significantly. There was no significant interaction between main effects. A significant positive linear relationship was found between initial and final root count. The results suggest a limited association between high initial adventitious root count and subsequent growth. Chemical name used: $1 \mathrm{H}$-indole-3-butyric acid (IBA).

Microculture presents a unique opportunity to investigate adventitious rooting. The environment from which microcuttings are derived can be managed to create biologically less variable plant material with greater rooting potential than macrocuttings that are produced in an ever-changing environment. Microcuttings are usually in a highly active growth state and often are considered to be physiologically parallel to "softwood" macrocuttings in rooting response (McCown, 1988).

Adventitious rooting of microcuttings has focused primarily on the in vitro rooting response even though ex vitro rooting of some plant species is practiced. Studies of in vitro and ex vitro rooting are restricted to a few weeks of root initiation and development. Limited information exists on the continued root initiation process and consequences of initial root count on plant growth ex vitro. Often, the future success of a rooted cutting is equated to quality and size of the adventitious root system (Hartmann et al., 1990).

Rooting apple microcuttings can be influenced by $\mathrm{pH}$ and the IBA concentration of the root initiation medium. At pH 5.5, $15 \mu \mathrm{M} \mathrm{IBA}$ induced $47 \%$ more roots than did $1.5 \mu \mathrm{M} \mathrm{IBA}$, whereas at $\mathrm{pH} 7.0$, the increase was $30 \%$. At $\mathrm{pH} 5.5,1.5 \mu \mathrm{M}$ IBA induced $92 \%$ more roots than at $\mathrm{pH} 7.0$, whereas at $15 \mu \mathrm{M}$ IBA, the increase was $116 \%$ (Harbage, 1991). The purpose of this study was to investigate the rela-

Received for publication 26 June 1992. Accepted for publication $14 \mathrm{Dec}$. 1992. The cost of publishing this paper was defrayed in part by the payment of page charges. Under postal regulations, this paper therefore must he hereby marked advertisement solely to indicate this fact.

'Professor.

${ }^{2}$ Graduate Research Assistant. tionship of the initial number of adventitious roots of' Gala' apple microcuttings on subsequent ex vitro root and shoot growth.

'Gala' apple cultures were obtained from Richard Zimmerman, U.S. Dept. of Agriculture, Beksville, Md. Shoots were subculture every 21 days on $100 \mathrm{ml}$ of modified Murashige-Skoog (MS) medium (Murashige and Skoog, 1962) supplemented with $0.56 \mathrm{~mm}$ myo-inositol, $1.2 \mu \mathrm{M}$ thiamine hydrochloride, $0.49 \mu \mathrm{M}$ IBA, $4.44 \mu \mathrm{m}$ benzyladenine, $1.3 \mu \mathrm{M}$ gibberellic acid, $88 \mathrm{~mm}$ sucrose, and $7 \mathrm{~g}$ Difco Bacto agar/liter (Zimmerman and Fordham, 1985).

Subculture consisted of basally detaching shoots, removing shoot tips, and slightly pressing each shoot tip horizontally into culture medium. Culture vessels consisted of 475-ml $(9.0 \times 9.5 \mathrm{~cm})$ clear glass jars covered with glass petri plate bottoms and a layer of plastic film. From 10 to 12 shoots were placed in each jar and incubated at $25 \mathrm{C}$ under continuous cool-white fluorescent light $\left(30 \mu \mathrm{mol} \cdot \mathrm{m}^{-2} \cdot \mathrm{s}^{-1}\right)$.

Shoots ( 1.5 to $2.0 \mathrm{~cm}$ long) were harvested for rooting 21 days after subculture. Shoots were covered with sterile water while in culture jars, detached at their bases with scissors, resubmerged in sterile water, and adjusted to shoot lengths having four to five expanded and solution $\mathrm{pH}$ during root initiation.

${ }^{2}$ Means of 30 observations, 18 days from start of root initiation.

$\mathrm{y} \pm \mathrm{SE}$. leaves from the shoot apex down $(=1.5 \mathrm{~cm}$ long) by cutting just above a node. Shoots were maintained in sterile water until placing them in the rooting treatments.

Root initiation treatments consisted of $\mathrm{O}$, $0.15,1.5,15$, and $150 \mu \mathrm{M}$ IBA in $10 \mathrm{~mm} 2-[-$ morpholino]ethanesulfonic acid (MES) and $43.8 \mathrm{~mm}$ sucrose adjusted to $\mathrm{pH}$ 5.5,6.3, and 7.0 with $1 \mathrm{~N} \mathrm{KOH}$ (Harbage, 1991). Root initiation was in darkness at 30C for 4 days (Zimmerman and Fordham, 1985). Hereafter, the first day of root initiation will be referred to as the start of root initiation.

Shoots were transferred to a root development phase medium of half-strength liquid MS major and minor elements and $21.9 \mathrm{~mm}$ sucrose. Incubation was for 14 days at $23 \mathrm{C}$ under a 16-h photoperiod provided by coolwhite fluorescent lamps $\left(30 \mu \mathrm{mol} \cdot \mathrm{m}^{-2} \cdot \mathrm{s}^{-1}\right)$. The number of initial adventitious roots was counted after 18 days from start of root initiation (Table 1). A root was considered to be adventitious if it originated from the stem. Initial root counts ranged from 1.7 to 19.6 (Table 1) and reflected $\mathrm{pH}$ and IBA levels (Harbage, 1991).

Root initiation and development were conducted in $25 \times 95-\mathrm{mm}$ glass vials $(40 \mathrm{ml})$. Each shoot was supported in the vial by placing the basal end of the microcutting through a $3-\mathrm{mm}$ hole in the center of a $20 \times 11-\mathrm{mm}$ plastic closure cap inserted into each vial. The basal 4-mm end of the microcutting was in the medium.

Rooted shoots were planted in fine vermiculite in plug trays, misted, and placed in a plastic box covered with a clear plastic lid after 18 days from start of root initiation. A $20 \mathrm{~N}-$ 8.7 $\mathrm{P}-16.6 \mathrm{~K}$ fertilizer spray at $50 \mathrm{mg} \mathrm{N} / \mathrm{liter}$ was applied to foliage twice weekly. On day 57 from start of root initiation, plants were transplanted to a 1 soil : 1 peat : 1 perlite medium, acclimated, and grown in the greenhouse. On day 85 , they were transplanted to the same medium in 580-ml containers. There were 10 replications per treatment. Plants were arranged in a completely random design. We determined plant height, final adventitious root count, leaf count and area (LI-3 100 area meter; LI-COR, Lincoln, Neb.), and root and shoot fresh and dry weights on day 149 from start of root initiation. A root was counted if it originated from the stem and a leaf was counted once it unfolded, but not necessarily expanded. Data were tested by analysis of variance.

There was no significant interaction between $\mathrm{pH}$ and IBA for characteristics measured; therefore, main effect means are pre-

Table 1. Number of adventitious roots on 'Gala' apple microcuttings as influenced by IBA concentration

\begin{tabular}{lrrrr}
\hline \hline IBA & \multicolumn{3}{c}{$\mathrm{pH}$} \\
\cline { 2 - 5 }$(\mu \mathrm{M})$ & \multicolumn{1}{c}{5.5} & 6.25 & 7.0 & Mean \\
\hline 0 & $1.7^{2} \pm 0.7^{y}$ & $6.5 \pm 1.0$ & 4.0 & 4.1 \\
0.15 & $7.7 \pm 1.0$ & $5.4 \pm 0.8$ & $1.7 \pm 0.8$ & 4.9 \\
1.5 & $12.4 \pm 1.8$ & $10.0 \pm 1.4$ & $4.9 \pm 1.4$ & 9.1 \\
15.0 & $19.6 \pm 2.6$ & $18.7 \pm 2.9$ & $6.1 \pm 1.8$ & 14.8 \\
150.0 & $9.9 \pm 2.2$ & $15.8 \pm 3.6$ & $11.6 \pm 3.1$ & 12.4 \\
\hline
\end{tabular}


sented (Table 2). The main effect of rootinitiation medium $\mathrm{pH}$ did not significantly affect results. However, root initiation IBA levels significantly influenced final root count and shoot fresh and dry weights. No difference in final average root count was observed between 0 and $0.15 \mu \mathrm{M}$ IBA, but at $1.5,15$, and $150 \mu \mathrm{M}$ IBA, root counts increased by $45 \%$, $141 \%$, and $159 \%$, respectively, over the control. These changes represent a significant quadratic response.

Shoot fresh and dry weights were lowest at 0 and $0.15 \mu \mathrm{M}$ IBA, highest at 1.5 and $15 \mu \mathrm{M}$ IBA, and intermediate at $150 \mu \mathrm{M}$ IBA in the rooting treatment. Leaf area data distribution was significant for the quadratic response. Leaves were hugest with rooting in $1.5 \mu \mathrm{M}$ IBA. There were no clear trends among data for plant height, leaf count, and root fresh and dry weights. Overall, values within each characteristic measured varied slightly, except for root count (Table 2).

A linear regression for initial root count at transplanting time and final root count at harvest on day 149 showed a significant positive linear relationship (Fig. 1 ). Microcuttings with fewer roots initially tended to produce fewer roots by experiment termination and, conversely, those with many roots initially produced more roots at the end $\left(r^{2}=0.264, P \leq\right.$ 0.05).

Plant survival from root initiation through experiment termination was associated with root-initiation IBA level. Plant survival was highest $(96.3 \%)$ with microcuttings rooted on $1.5 \mu \mathrm{M}$ IBA (Table 3). Lower survival occurred at $0,0.15,15$, and $150 \mu \mathrm{m}$ IBA. Survival differences due to root-initiation IBA treatment were not apparent until 57 days after treatment and remained mostly unchanged through 116 days. Survival was lowest with $150 \mu \mathrm{M}$ IBA.

The data presented demonstrate that adventitious root development on 'Gala' apple microcuttings was not completed within 18 days from the start of root initiation, but continued ex vitro. The magnitude of this development was linked to the IBA level used during root initiation. Previous anatomical analysis of 'Gala' microcuttings 4 days after treating them with or $1.5 \mu \mathrm{M}$ IBA revealed synchronous root primordia initiation at 0 to 2 and 10 to 12 initiation sites, respectively (Harbage, 1991). By 14 days, these initials emerged as roots, with no additional root emergence 1 week later. Our study shows that after 149 days of growth, microcuttings rooted with $1.5 \mu \mathrm{M}$ IBA developed 74 adventitious roots, about a 7.4 -fold increase (Table 1). The fact that 10 to 12 root initials were visible anatomically 4 days after IBA treatment, but that final root counts were higher, implies that adventitious root development is not a discrete process confined to the period immediately after IBA treatment. Growth-limiting factors appear to set a maximum root count load for root initiation and development, with the final root count perhaps based on episodic waves of root initiation and development.

Manipulating rooting medium $\mathrm{pH}$ and IBA concentration influenced initial adventitious

Table 2. Influence of auxin level and solution $\mathrm{pH}$ on rooted 'Gala' apple microcuttings 149 days from the start of root initiation.

\begin{tabular}{|c|c|c|c|c|c|c|c|c|}
\hline \multirow[b]{3}{*}{ Treatment } & \multirow{3}{*}{$\begin{array}{c}\mathrm{Ht} \\
(\mathrm{cm})\end{array}$} & \multirow{3}{*}{$\begin{array}{l}\text { Root } \\
\text { count }\end{array}$} & \multicolumn{2}{|c|}{ Leaf } & \multirow{2}{*}{\multicolumn{2}{|c|}{ Fresh wt (g) }} & \multicolumn{2}{|c|}{ Dry wt } \\
\hline & & & \multirow[b]{2}{*}{ No. } & \multirow{2}{*}{$\begin{array}{l}\text { Area } \\
\left(\mathrm{cm}^{2}\right)\end{array}$} & & & \multirow{2}{*}{$\begin{array}{l}\text { Shoot } \\
\text { (g) }\end{array}$} & \multirow{2}{*}{$\begin{array}{l}\text { Root } \\
(\mathrm{mg})\end{array}$} \\
\hline & & & & & Shoot & Root & & \\
\hline \multicolumn{9}{|l|}{$\mathrm{pH}^{\mathrm{z}}$} \\
\hline 5.5 & 53.0 & 82 & 28 & 613 & 16.2 & 4.9 & 5.2 & 790 \\
\hline 6.25 & 53.5 & 65 & 28 & 607 & 15.9 & 5.3 & 5.1 & 858 \\
\hline 7.00 & 50.6 & 84 & 28 & 616 & 15.8 & 5.2 & 5.0 & 803 \\
\hline \multicolumn{9}{|l|}{ IBA $(\mu \mathrm{M})^{\mathrm{y}}$} \\
\hline 0 & 51.2 & 51 & 28 & 600 & 15.3 & 5.0 & 4.9 & 800 \\
\hline 0.15 & 51.7 & 51 & 28 & 593 & 15.3 & 4.8 & 4.9 & 778 \\
\hline 1.5 & 54.3 & 74 & 29 & 633 & 16.6 & 5.4 & 5.3 & 881 \\
\hline 15.0 & 51.9 & 123 & 28 & 618 & 16.6 & 5.4 & 5.3 & 824 \\
\hline 150.0 & 51.6 & 132 & 28 & 615 & 15.7 & 4.8 & 5.1 & 675 \\
\hline \multicolumn{9}{|c|}{ Analysis of variance } \\
\hline $\mathrm{pH}$ & NS & NS & NS & NS & NS & NS & NS & NS \\
\hline IBA & NS & $* * *$ & NS & NS & * & NS & * & NS \\
\hline Linear & NS & NS & NS & NS & NS & NS & NS & NS \\
\hline Quadratic & NS & ** & NS & * & * & NS & * & NS \\
\hline $\mathrm{pH} \times \mathrm{IBA}$ & NS & NS & NS & NS & NS & NS & NS & NS \\
\hline
\end{tabular}

${ }^{2}$ Means of 30 to 32 observations.

yeans of 19 to 26 observations.

$*, * *, * * *, N S$ Significant at $P \leq 0.05,0.01,0.001$, or not significant, respectively,

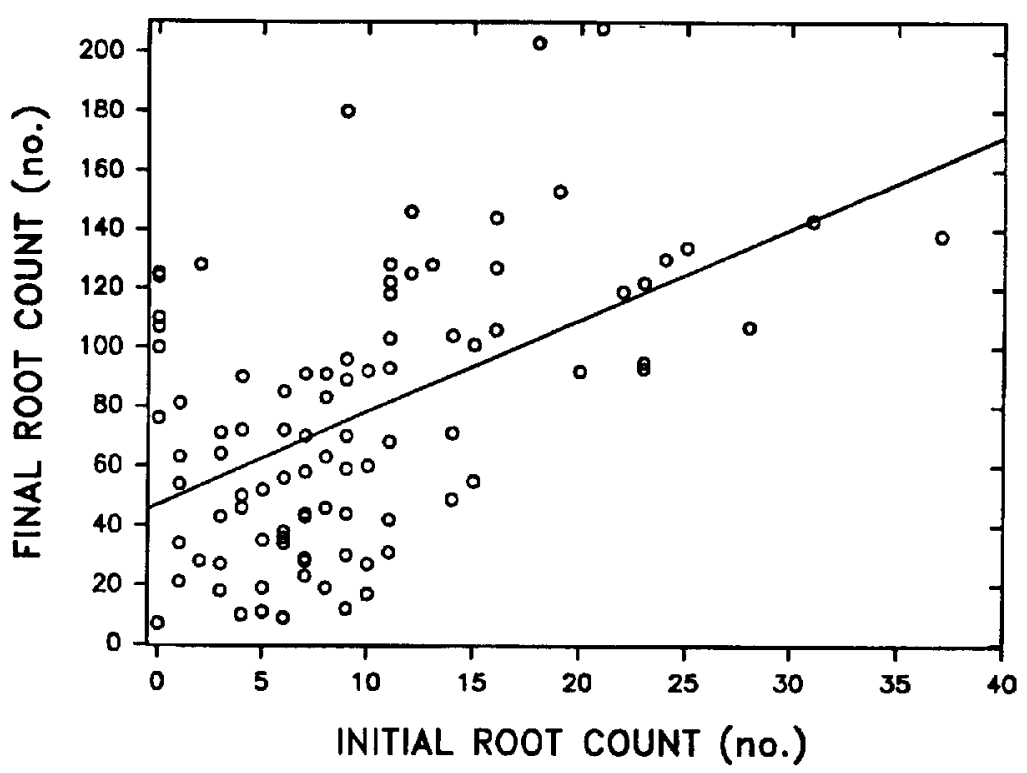

Fig. 1. Linear regression of final vs. initial root count of rooted 'Gala' apple microcuttings.

root counts observed at transplanting (Table 1). Under more acidic levels near $\mathrm{pH} 4.75$ for IBA and under increasing IBA levels from $\mathrm{O}$ to $15 \mu \mathrm{M}$, the number of adventitious roots increased (Harbage, 1991). From a horticultural perspective, this treatment appears to have limited value, since the number of adventitious roots at ex vitro transplanting apparently failed to influence significantly most shoot growth responses observed by 149 days (Table 2). However, from a biological perspective, the influence of $\mathrm{pH}$ on initial root counts warrants further investigation and may be of horticultural value on other plants.

Previous research reported that the number of roots initiated per cutting maybe a function of the amount of auxin-like substances in the rooting zone (Bastin, 1966; Hemberg, 1954). Odom and Carpenter ( 1965) showed a positive relationship between levels of exogenously applied auxins and endogenous auxins and rooting response, which suggests that opti- mum endogenous auxin levels were required for rooting. A reduced level of endogenous auxin has been implicated in rooting failure in cuttings of various plant species (Cooper, 1 935; Smith and Wareing, 1972a, 1972b). In other cases, auxin levels did not appear to be limiting (Biran and Halevy, 1973; Greenwood et al., 1976). Our data suggest that applied IBA levels influenced root counts shortly (Table 1) and long after (Table 2) application. Also, without IBA application, the initial root count was lowest, but increased 25 -fold from the initial count over the experiment duration. Therefore, auxin does not appear to be limiting adventitious root formation in 'Gala'. The enhanced and continued rooting stimulation after a short exposure to IBA during root initiation suggests residual IBA is present and available for continued rooting in shoot tissue. Exogenously applied IBA is converted into IBA conjugates, such as IBA-aspartate, in plant tissue (Wiesman et al., 1988). Conju- 
Table 3. Percent survival of 'Gala' apple plantlets over time.

\begin{tabular}{lcccc}
\hline \hline IBA & $\begin{array}{c}\text { Root initiation } \\
\text { (18 days) }^{\mathrm{z}}\end{array}$ & $\begin{array}{c}\text { Transplanting I } \\
\text { (57 days) }\end{array}$ & $\begin{array}{c}\text { Transplanting II } \\
\text { (85 days) }\end{array}$ & $\begin{array}{c}\text { Harvest } \\
\text { (149 days) }\end{array}$ \\
\hline $\mathbf{M}$ & $100^{\mathrm{y}}$ & 70.3 & 70.3 & 70.3 \\
0.15 & 100 & 81.3 & 81.7 & 81.7 \\
1.5 & 100 & 96.3 & 96.3 & 96.3 \\
15.0 & 100 & 81.7 & 81.7 & 78.0 \\
150.0 & 100 & 22.3 & 22.3 & 15.0 \\
\hline
\end{tabular}

${ }^{2}$ Days from start of root initiation.

'Based on 27 observations.

gated auxin forms have been implicated in promoting adventitious rooting (Weisman et al., 1989). In 'Gala', microcuttings readily metabolize applied IBA into IBA-aspartate (Harbage, 1991)

The number of adventitious roots varied among IBA levels used during root initiation. However, variation among means for plant height, leaf count and area, and fresh and dry weights of roots and shoots remained small. This result suggests that adventitious root count becomes a moot point when considering its role in plant growth. The equalization of root weights irrespective of root count suggests that root weight or perhaps root volume is more critical than root count in supporting growth. This equalization would suggest that, to establish integrated root and shoot growth, the shoot is the stronger modulator of control and regulates root development even though many adventitious roots were present in some treatments. The threshold of minimum adventitious root count, however, remains unknown. Frequently, in cuttage propagation, success is equated with attaining many roots rapidly. In contrast, our data suggest that a minimum root count coupled with a more critical root weight determines microcutting survival.

The carryover effect of auxin following adventitious rooting has been documented on macrocuttings and reported to inhibit budbreak and root growth, resulting in plant death (Hartmann et al., 1990). Plant survival of rooted 'Gala' microcuttings appeared to be influenced by the IBA level used for root initiation (Table 3). Plant survival declined with $15 \mu \mathrm{M}$ IBA and was lowered further at $150 \mu \mathrm{m}$ IBA. Although the highest root counts were attained at $15 \mu \mathrm{M}$ IBA (Harbage, 1991), in view of the survival data, there seems to be an apparent maximum load of 10 to 12 roots growth response occurs with more roots. This result implies that root weight or root volume are more crucial to rapid plant growth than high adventitious root counts. A 1.5- $\mu \mathrm{M}$ IBA root initiation treatment should be used as the optimum treatment for 'Gala'.

\section{Literature Cited}

Bastin, M. 1966. Root initiation, auxin level and biosynthesis of phenolic compounds. Photochem. Photobiol. 5:423-429.

Biran, I. and A.H. Halevy. 1973. Endogenous levels of growth regulators and their relationship to the rooting of dahlia cuttings. Physiol. Plant. 28:244247.

Cooper, W.C. 1935. Hormones in relation to root formation on stem cuttings. Plant Physiol. 10:789-794. per microcutting. No additional gain in shoot
Greenwood, M. S., O.R. Atkinson, and H.W. Yawney. 1976. Studies of hard- and easy-toroot ortets of sugar maples: Difference not due to endogenous auxin content. Plant Propagator 22:3-6.

Harbage, J.F. 1991. Anatomy and physiology of adventitious root formation in Malus domestica microcuttings. PhD Diss., Univ. of Wisconsin, Madison. (Diss. Abstr. 91-28915).

Hartmann, H.T., D.E. Kester, and F.T. Davies. 1990. Plant preparation. Prentice Hall, Englewood Cliffs, N.J.

Hemberg, T. 1954. The relation between the occurrence of auxin and the rooting of hypocotyls in Phaseolus vulgaris L. Physiol. Plant. 7:323331.

McCown, B.H. 1988. Adventitious rooting of tissue cultured plants, p. 289-302. In: T.D. Davis, B.E. Haissig, and N. Sankhla (eds.). Adventitious root formation in cuttings. Dioscorides Press, Portland, Ore

Murashige, T. and F. Skoog. 1962. A revised medium for rapid bioassays with tobacco tissue cultures. Physiol. Plant. 15:473-497.

Odom, R.E. and W.J. Carpenter. 1965. The relationship between endogenous indole auxins and the rooting of herbaceous cuttings. Proc. Amer. Soc. Hort. Sci. 87:494-501.

Smith, D.R. and P.F. Wareing. 1972a. Rooting of hardwood-cuttings in relation to bud dormancy and the auxin content of the excised stems. New Phytol. 71:63-80.

Smith, D.R. and P.F. Wareing. 1972b. The rooting of actively growing and dormant leafy cuttings in relation to the endogenous hormone levels and photoperiod. New Phytol. 71:483-500.

Wiesman, Z., J. Riov, and E. Epstein. 1988. Comparison of movement and metabolism of indole3 -acetic acid and indole-3-butyric acid in mung bean cuttings. Physiol. Plant. 74:556-560.

Wiesman, Z., J. Riov, and E. Epstein. 1989. Characterization and rooting ability of indole-3-butyric acid conjugates formed during rooting of mung bean cuttings. Plant Physiol.91:1080-1084.

Zimmerman, R.H. and 1. Fordham. 1985. Simplified method for rooting apple cultivars in vitro. J. Amer. Soc. Hort. Sci. 110:34-38. 